\title{
IMPROVEMENT OF SURFACE PROPERTIES BY BURNISHING ON
}

\author{
ALUMINIUM ALLOY \\ V. S. N. VENKATA RAMANA, YASH NAIDU, T. V. NARAYANA REDDY \& V. SRINIVAS \\ Gandhi Institute of Technology and Management (Deemed to be) University,
}

Visakhapatnam, Andhra Pradesh, India

\begin{abstract}
In roller burnishing is process, a hard and highly polished roller is pressed against a rotating component. This results in the plastic flow of material from the peaks of surface irregularities into the valleys, thereby reducing the surface roughness. The pressure applied causes the cold working of the component's surface which in turn improves micro-hardness, induces compressive stresses and refines the microstructure. This improvement in properties has a positive impact on the surface characteristics like corrosion resistance, wear resistance; fatigue life etc. The aim of the present research work is to study the feasibility of roller burnishing process, in enhancing the surface properties. The surface roughness, micro-hardness and micro-structure were examined in this work. Experimental work was carried out to determine the effect of roller burnishing on these characteristics for aluminium AA6063- T6. From the results obtained from the experiments, it was clearly observed that the effect of roller burnishing on improving some of the desired material properties was immense. It is observed that roller burnishing can be adopted as the surface finishing process to improve the surface properties of the component.
\end{abstract}

KEYWORDS: Roller Burnishing, Surface Roughness, Micro Hardness \& AA6063

Received: Mar 11, 2018; Accepted: Apr 02, 2018; Published: Jul 25, 2018; Paper Id.: IJMPERDAUG201871

\section{INTRODUCTION}

Surface modifications and surface treatments play vital role in enhancing service life of many critical parts of materials and devices that are used for engineering and/or structural applications. Modern technologies employ advanced surface modification techniques, such as laser treatment and coatings to enhance service life. However, it is observed that these advanced technologies are expensive and economically unviable for most of the applications like for automobiles and machine parts. In these circumstances, traditional surface modification techniques that result in surface roughness values of the order of 0.1 to $0.2 \mu \mathrm{m}$ are desirable. Burnishing is one such cold working and chip less process which produces a smooth surface and improved surface hardness.

Hardened and highly polished steel rollers are brought into pressure contact with a soft work piece. This applied pressure exceeds the yield point of the work piece material, and the surface will be plastically deformed by cold- flowing of subsurface material. The result of burnishing process is condensation of grain structure, refined and compacted smooth surface, hardened and a layer of more wear resistance than ground or honed surface. The burnishing tool forces the material from the peaks to flow into the valleys when the force is applied. This reduces the height of the peaks and depth of the valleys, thereby reducing the surface roughness. Abrasive metal removal methods lower the roughness height. Interestingly, they leave sharp projections in the contact plane of the machined surface [1]. It is observed that a burnished surface is smoother than an abrasively 
finished surface of the same profilometer reading. The Roller burnishing helps users to avoid secondary operations for substantial time and cost savings, while at the same time improving the quality of their product. It distinguishes itself from chip-forming finishing processes such as grinding, honing, lapping and super finishing, which induce residual tensile stresses at the surface, while burnishing results in residual compressive stresses. The fatigue resistance and wear resistance improvement are observed due to induced residual compressive stresses on the surface of the burnished components [2]. The changes in the surface characteristics due to burnishing will cause improvements in surface hardness, surface roughness, wear resistance, fatigue and corrosion resistance as claimed by many authors [1 \& 3-5] which in turn improve corrosion resistance, wear resistance[4, 12-13], tensile strength [1], larger maximum residual stress in compression [9-11] and better roundness [12].

In literature it is reported that Severe plastic deformation (SPD) processes have been extensively used for modifying surface region properties by creating ultrafine or nanometer-sized grains and grain size gradients in the surface region of many products. Proofs have shown that SPD induced nano-sized/ultrafine grained materials possess appealing surface integrity properties compared with their coarse-grained counterparts [13-15]. Burnishing is also an SPD process with high strain and strain-rate [15]. Considerable grain refinement has been reported in the processed surface layers of various metals and alloys. The refined surface layers in general show better corrosion resistance than their large grain counterparts. Prevey and co-workers $[17,18]$ observed that low plasticity burnishing can provide a layer of compressive residual stress with sufficient depth to effectively increase the fatigue life of many materials. Hamadache et al. [19] observed $89 \%$ wear improvement and up to $9 \%$ hardness improvement compared to the sample made by turning after roller burnishing of structural Rb40 steel. Radziejewska et al. [20] observed a $40 \%$ reduction of wear rate from burnishing after laser alloying of carbon steels with cobalt stellite.

Moreover, burnishing is economical and requires less time and skill to obtain a high quality surface finish. The study of surface finish that results from burnishing is highly important because the fatigue life, bearing properties and lubrication of a part depends largely on the appropriate surface finish [21], which ultimately decides the effectiveness of burnishing process.

In order to increase the life of any part which is subjected to repeated reversals of stress, the working and non-working surfaces of that part must be given good surface finish as economically as possible. Constant surface roughness can be achieved over a wide range of process conditions through hard roller burnishing [2, \& 22- 28].

\section{EXPERIMENTAL DETAILS}

In the present work, aluminium alloy A6063-T6 was considered as base metal in the form of rod of length 2 feet and outer diameter $20 \mathrm{~mm}$. The chemical composition of the base metal is given in Table 1. A6063-T6 is a medium strength alloy commonly. It possess good surface finish, high corrosion resistance, readily weldable and can be easily anodized. The burnishing tool (Figure 1) was constructed with the help of a Roller bearing, helical compression spring $(\mathrm{k}=15.696 \mathrm{~N} / \mathrm{mm})$ and a Bush $(\mathrm{L}=43 \mathrm{~mm})$. The work pieces were first machined on a lathe machine (Figure 2). Later the machined samples were burnished (Figure 3$)$ at a constant feed of $(0.14 \mathrm{~mm} / \mathrm{rev})$, constant speed of $160 \mathrm{rpm}$ and at varying forces viz. $6,12,18,24,30 \mathrm{kgF}$ on each rod and the coolant used during burnishing was kerosene.

The burnished and unburnished samples were tested for surface roughness on Mitutoyo surface roughness testing equipment. The hardness of the surface of both burnished and unburnished samples were measured by Vickers Hardness 
equipment. The microstructure of the burnished and un-burnished surfaces was observed for any refinement in the grain structure, using an optical microscope. To study the effect of burnishing on corrosion resistance after burnishing, Pitting corrosion test was conducted. The electrical conductivity of specimen before and after burnishing was measured using the Kelvin Double Bridge.

Table 1: Composition of Base Metal AA6063

\begin{tabular}{|c|c|c|c|c|c|c|c|c|}
\hline Element & Silicon & Iron & Copper & Magnesium & Chromium & Zinc & Titanium & Aluminum \\
\hline Wt. $\%$ & $0.4 \%$ & $0.35 \%$ & $0.10 \%$ & $0.6 \%$ & $0.10 \%$ & $0.10 \%$ & $0.10 \%$ & Remaining \\
\hline
\end{tabular}

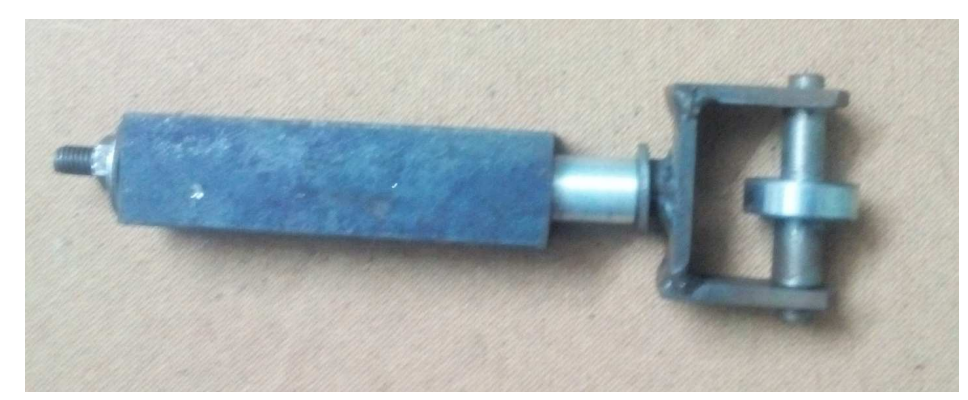

Figure 1: Burnishing Tool

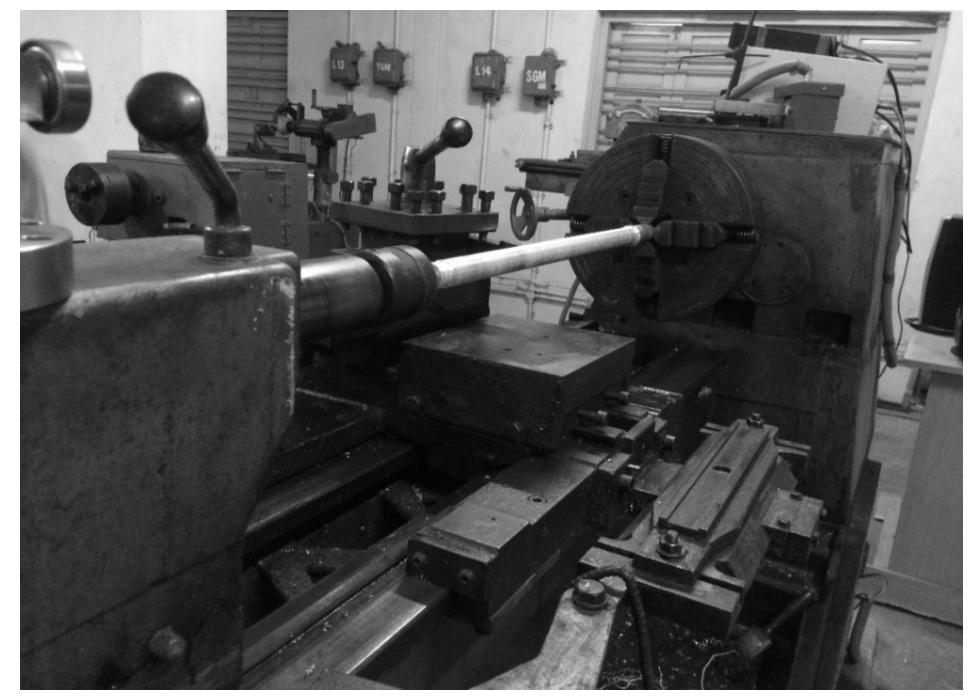

Figure 2: The Setup Used for Machining on Lathe

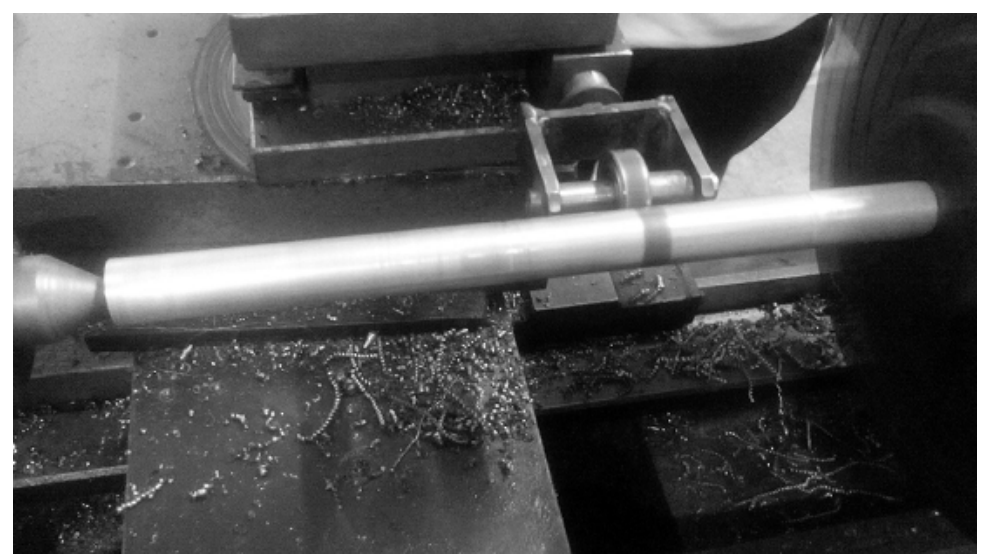

Figure 3: Burnishing Process 


\section{RESULTS AND DISCUSSIONS}

\section{Surface Roughness}

The surface roughness of specimen before and after the burnishing process was measured by surface roughness tester and the values are represented in a graph and are shown in Figure 4. The values clearly show that after burnishing the surface roughness of the specimen was reduced drastically by about $85 \%$. The least value of roughness obtained was $0.41 \mu \mathrm{m}$ at $12 \mathrm{kgF}$ force. It is observed form the above data and graphs that there is a considerable decrease in surface roughness after burnishing process. The roughness reduced as the burnishing force is increased, however no clear relation can be stated when the speed is increased. The best surface finish was obtained for a sample which was subjected to a burnishing force $12 \mathrm{kgF}$.

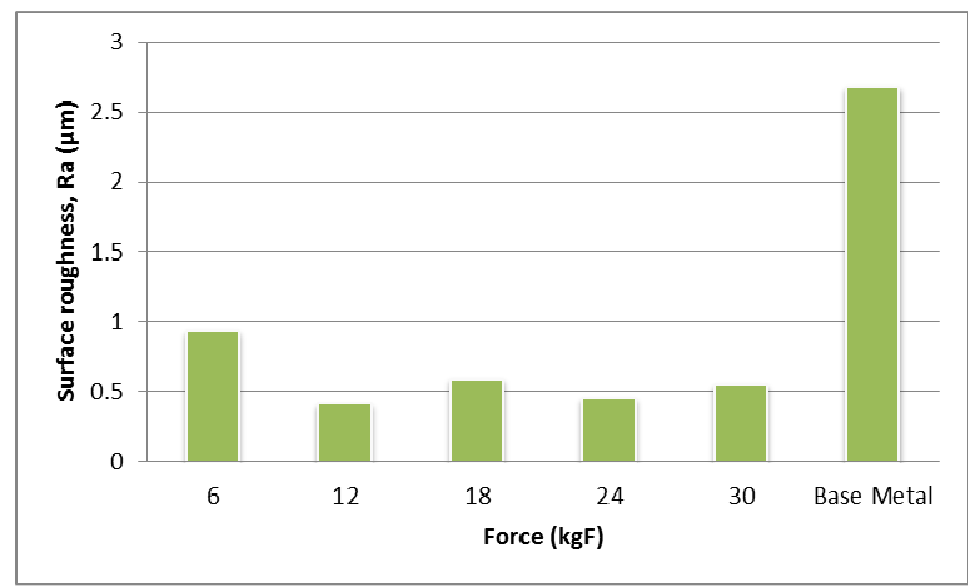

Figure 4: Surface Roughness Values (Ra) of Base Metal and Burnished Samples at Different Forces

\section{Micro Hardness}

Before and after the burnishing process hardness of the specimen were measured and the values are represented in a graph and are shown in Figure 5. There is considerable improvement in hardness after burnishing and is around 10\%. It is noted that the highest hardness was observed when the burnishing force is $12 \mathrm{kgF}$. It is attributed to the fine size and uniform distribution of the eutectics at $12 \mathrm{kgF}$ compared to other forces.

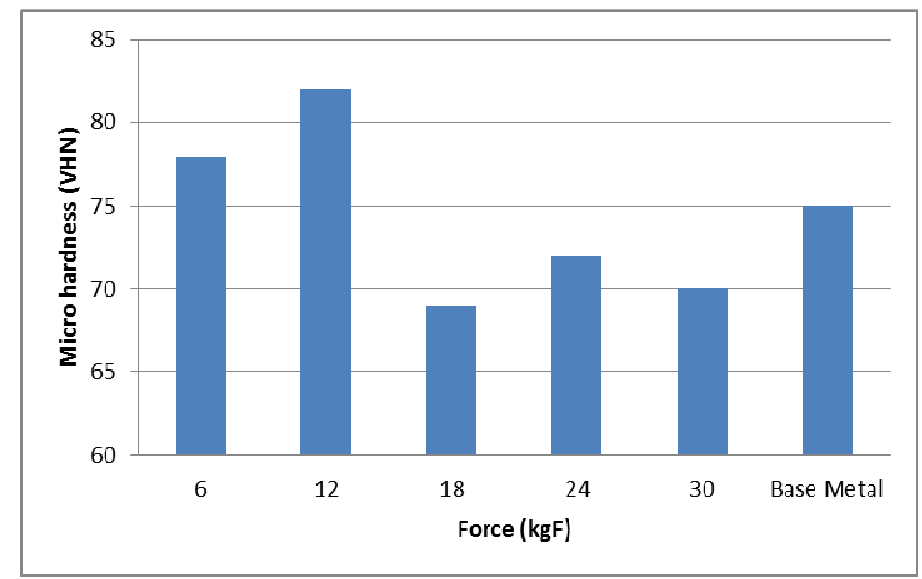

Figure 5: Hardness Values of AA6063 before and after Burnishing at Different Forces 


\section{Microstructure Analysis}

Optical microstructures are observed before and after burnishing and are shown in Figure 6. From these microstructures it is evident that the eutectics became fine and distributed evenly when the force is $12 \mathrm{kgF}$ (Figure $6 \mathrm{c}$ ). Beyond this force, the eutectics were randomly distributed.
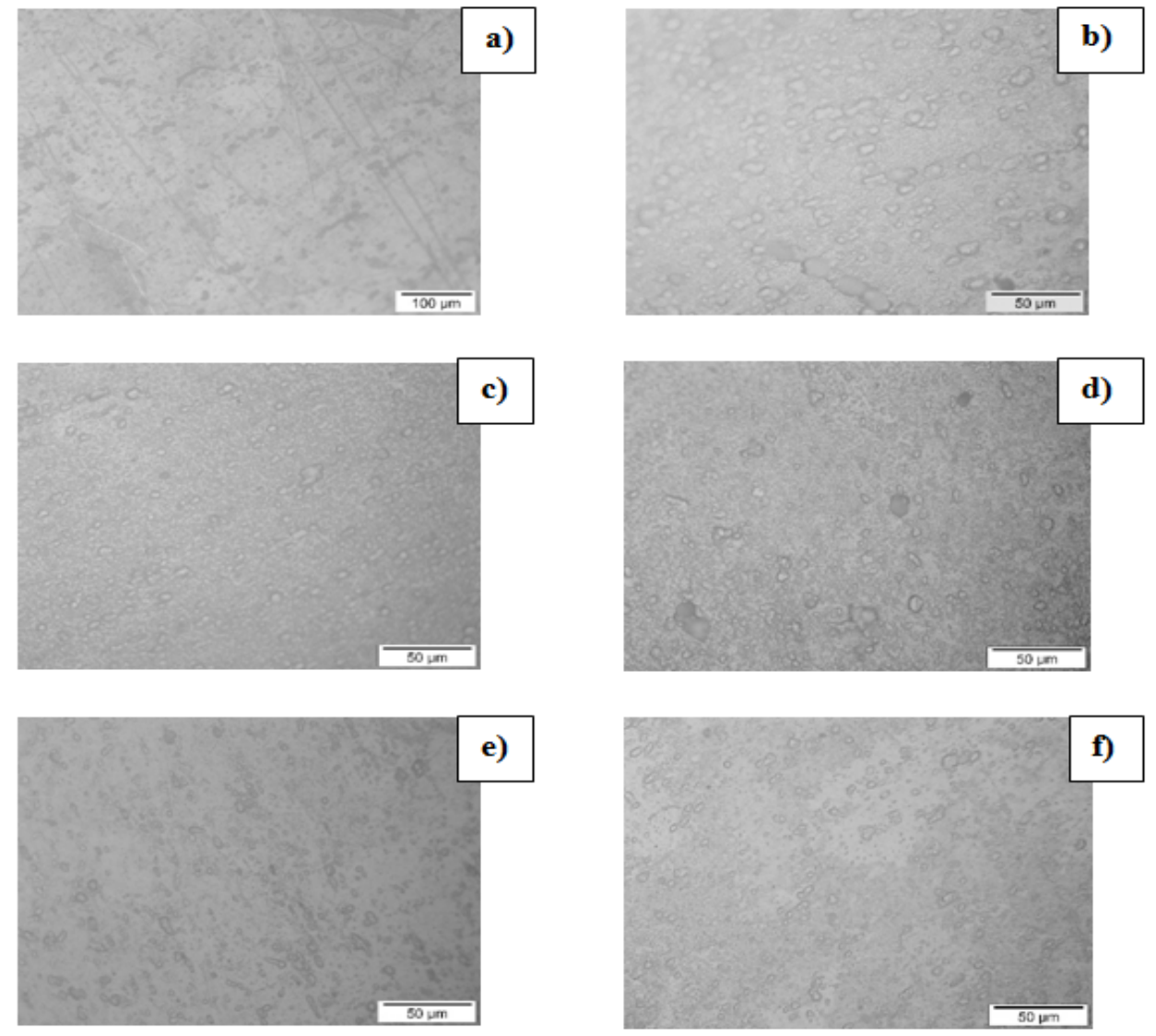

Figure 6: Optical Microstructures of Base Metal and Burnished Specimen (a) Base Metal, (b) Burnished at 6kgF (c) Burnished at $12 \mathrm{kgF}$, (d) Burnished at $18 \mathrm{kgF}$, (e) Burnished at $24 \mathrm{kgF}$, (f) Burnished at $30 \mathrm{kgF}$

\section{CONCLUSIONS}

- The surface roughness of the machined surface was drastically reduced after the burnishing process. The minimum surface roughness was observed at $12 \mathrm{kgF}$ force.

- The surface hardness of aluminium alloy specimens increases with increase in the burnishing force up to $12 \mathrm{kgF}$. With further increase in burnishing force there is decrease in surface hardness of the specimens.

- The eutectics were fine with increase in force and beyond $12 \mathrm{kgF}$ force the distribution of eutectics become uneven. 


\section{REFERENCES}

1. Murthy R.L., and Kotiveerachari B. (1981). "Burnishing of Metallic Surfaces - A Review”, Precision Engineering Journal, 3, pp 172-179.

2. Shneider. G. (1967). “Characteristics of burnished components”, Mechanical Tooling Journal, 38, pp 19-22.

3. A.M. Hassan (1997). The effects of ball and roller burnishing on the surface roughness and hardness of some non-ferrous metals, Journal of Materials Processing Technology, 72, 385-391.

4. R. Rajaselkariah, S. Vaidyanathan (1975). Increasing the wear resistance of steel components by ball burnishing, Wear, 34183-188.

5. A.M. Hassan, A.S. Al-Bsharat (1969). Influence of in some properties of non-ferrous metals by the application of ball burnishing process, Journal of Materials Processing Technology, 59/3, 250-256.

6. Yu.G. Sheneider (1967). Characteristics of burnished components, Mechanical Tooling, 38/1, 19-22.

7. R. Narayan (1988). Corrosion resistance of ball burnished components, Proceedings of the 13th Scientific AIMTDR Conference, Jadavpur, 6-10.

8. N.L. Neema, P.C. Pandy (1996). Investigation of the performance characteristics of cold worked machined surfaces, Wear, 60/1, 157-166.

9. T. Morimoto, K. Tamamura (1991). Burnishing process using a rotating ball tool-effect of tool material on the burnishing process, Precision Engineering, 10, 185-193.

10. M.H. El-Axir (2000). An investigation into roller burnishing, International Journal of Machine Tool Manufacture, 40, 16031617.

11. M. Fattouh, M.M. El-Khabeery (1989). Residual stress distribution in burnishing solution treated and aged 7075 aluminium alloy, International Journal Machine Tool Manufacture, 29/1, 153-160.

12. F. Klocke, J. Liermamnn (1998). Roller burnishing of hard turned surface, International Journal of Machine Tool Manufacture, 38/5-6, 419-423.

13. Wang ZB, Tao NR, Li S, Wang W, Liu G, Lu J, Lu K (2003). Effect of surface nanocrystallization on friction and wear properties in low carbon steel, Mater. Sci. Eng., 352:144-49.

14. Shi YN, Han Z (2008). Tribological behaviors of nanostructured surface layer processed by means of surface mechanical attrition treatment, Key Eng. Mater., 384:321-34.

15. Qi Z, Jiang J, Meletis EI (2009). Wear mechanism of nanocrystalline metals, J Nanosci Nanotechnol., 9:4227-32.

16. Skalski K, Morawski A, Przybylski W(1995), Analysis of contact elastic-plastic strains during the process of burnishing, Int. J. Mech. Sci., 37:461-72.

17. Prevey P, Cammett J (2001). Low cost corrosion damage mitigation and improved fatigue performance of low plasticity burnished 7075-T6, J. Mater. Eng. Perform., 10:548-55.

18. Prevey P, Telesman J, Gabb T, Kantzos P (2000). FOD resistance and fatigue crack arrest in low plasticity burnished IN718, In: Proceedings of the 5th Nat. Turbine Eng. HCF Conf.,.

19. Hamadache H, Laouar L, Zeghib NE, Chaoui K (2006). Characteristics of Rb40 steel superficial layer under ball and roller burnishing, J. Mater. Process. Technol., 180:130-36. 
20. Radziejewska J, Nowicki B, Kalita W (2005). Hybrid method for modification of surface layer, In: Proc. 13th Intern. Sci. Conf. CO-MAT-TECH, Trnava, Slovakia, p. 111-16.

21. Chepa P A and Andrayshin V A (1973). Residual stresses in components work hardened by burnishing. Russian Eng. J., 53: $34-35$

22. Vyallo A A (1965). Combined turning and burnishing operations, Machines and Tooling, 36: 27-29

23. Sheider Yu G (1970). Contact area of vibro-burnished surfaces, Russian Eng. J., L: 34-39

24. Jack R Clark and Marion B Grant (1992). The effect of surface finish on component performance, Int. J. Mech. Tools Manufact., 32: 57-66

25. Brinksmeier E (1982). Residual stresses measurement and causes in machining process, Annals of the CIRP 31: 491-510

26. Kotiveerachari B and Murthy RL (1988). Estimation of depth of plastic deformation layer in burnishing. Proceeding of 13th ATMIDR, Calcutta D24-D30

27. Kotiveerachari B and Murthy RL (1989). Study of some aspects of burnishing. Int. J. Production Res. 23: 499-521

28. Phillip J Ross (2008). Taguchi techniques for quality engineering. Noida, India: TATA Mc-GRAW Hill. 
